\title{
Effects of manganese oxide and sulphate on the olefin selectivity of iron catalysts in the Fischer Tropsch reaction
}

\section{Citation for published version (APA):}

Dijk, van, W. L., Niemantsverdriet, J. W., Kraan, van der, A. M., \& van der Baan, H. (1982). Effects of manganese oxide and sulphate on the olefin selectivity of iron catalysts in the Fischer Tropsch reaction. Applied Catalysis, 2(4-5), 273-288. https://doi.org/10.1016/0166-9834(82)80074-2

DOI:

10.1016/0166-9834(82)80074-2

Document status and date:

Published: 01/01/1982

\section{Document Version:}

Publisher's PDF, also known as Version of Record (includes final page, issue and volume numbers)

\section{Please check the document version of this publication:}

- A submitted manuscript is the version of the article upon submission and before peer-review. There can be important differences between the submitted version and the official published version of record. People interested in the research are advised to contact the author for the final version of the publication, or visit the $\mathrm{DOI}$ to the publisher's website.

- The final author version and the galley proof are versions of the publication after peer review.

- The final published version features the final layout of the paper including the volume, issue and page numbers.

Link to publication

\section{General rights}

Copyright and moral rights for the publications made accessible in the public portal are retained by the authors and/or other copyright owners and it is a condition of accessing publications that users recognise and abide by the legal requirements associated with these rights.

- Users may download and print one copy of any publication from the public portal for the purpose of private study or research.

- You may not further distribute the material or use it for any profit-making activity or commercial gain

- You may freely distribute the URL identifying the publication in the public portal.

If the publication is distributed under the terms of Article 25fa of the Dutch Copyright Act, indicated by the "Taverne" license above, please follow below link for the End User Agreement:

www.tue.nl/taverne

Take down policy

If you believe that this document breaches copyright please contact us at:

openaccess@tue.nl

providing details and we will investigate your claim. 
W.L. van DIJK ${ }^{\star}$, J.W. NIEMANTSVERDRIET ${ }^{\dagger}$, A.M. VAN DER KRAAN ${ }^{\dagger}$ and H.S. VAN DER BAAN Laboratory of Chemical Technology, Eindhoven University of Technology, P.0.B. 513, 5600 MB Eindhoven, The Netherlands.

tInteruniversitair Reactor Institute Delft, The Netherlands.

*Present address: ESSO Nederland BV, Rotterdam, The Netherlands.

(Received 27 July 1981, accepted 18 December 1981)

\section{ABSTRACT}

Al though it has been claimed by various authors that the addition of manganese oxide, Mno, to an iron catalyst gives a marked increase in the olefin selectivity of iron catalysts, we have been unable to confirm these claims in Fischer Tropsch experiments at $513 \mathrm{~K}$ for an iron manganese oxide catalyst made from P.A. chemicals. After the initial very low activity of the catalyst, the increase in activity is associated with an increase of the ethane to ethene ratio. This increase is explained in terms of the formation of special hydrogenation ensembles. The iron manganese oxide catalyst was also studied during Fischer Tropsch synthesis with Mossbauer spectroscopy and $X$-ray diffraction. These investigations also failed to find differences between a pure iron catalyst, on which we have reported previously, and an iron manganese oxide catalyst. The latter catalyst forms in the course of a Fischer Tropsch synthesis experiment at $513 \mathrm{~K}$ about the same quantities of the carbides $X-\mathrm{Fe}_{5} \mathrm{C}_{2}, \varepsilon^{\prime}-\mathrm{Fe}_{2.2} \mathrm{C}$ and $\mathrm{Fe} \mathrm{C}$ as a pure iron catalyst.

At $623 \mathrm{~K}$ the iron manganese catalyst deactivates quickly and selectively produces methane, However, when small quantities of a sulphate salt are added to an iron manganese oxide catalyst it remains rather stable at $623 \mathrm{~K}$ and produces light olefins very selectively. The production of methane as well as the deposition of carbon are hindered by this sulphate treatment.

\section{INTRODUCTION}

An intensive research effort is at present directed towards the development of iron catalysts which are selective for the production of light olefins.

Kölbel et al. [1] prepared olefin selective catalysts with a low iron to manganese atomic ratio $(1: 9)$. Before the start of the Fischer Tropsch synthesis, their catalysts were activated with carbon monoxide at $513 \mathrm{~K}$. Bissemeier et al. [2] developed an olefin selective catalyst by fusing iron catalysts with an iron: manganese atomic ratio of $(1: 1)$. They observed a low methane production, deviating very greatly from the Schulz-Flory distribution. Compared to a pure iron catalyst, 
Yang and oblad [3] observed in their iron manganese oxide catalysts an increased olefin selectivity even at a high iron to manganese atomic ratio (20:1).

In a previous publication [4], we described the behaviour of a pure iron catalyst during the Fischer Tropsch synthesis at $513 \mathrm{~K}$ and $100 \mathrm{kPa}$. The composition of the catalysts was investigated by Mössbauer spectroscopy and $X$-ray diffraction analysis. When carburized, that catalyst showed an ethane/ethene ratio of about 0.2 in the steady state, while the product distribution agreed well with the Schulz-Flory prediction.

In the present investigation we have studied the promotor effect of manganese oxide on Fischer Tropsch catalysts. Since it has been long known from the patent literature $[5,6,7]$ and more recently from the work of Dalla Betta et al. [8], that the addition of small quantities of a sulphur containing compound resulted in an enhanced olefin content of the products, we have investigated that effect also. A review of the effect of sulphur is given by Madon and Shaw [9].

\section{EXPERIMENTAL}

\section{Catalyst preparation}

The iron manganese oxide catalysts were prepared by slowly adding ammonium hydroxide (12 wt \% ammonia, Merck P.A., $45 \mathrm{~mm}^{3} \mathrm{~s}^{-1}$ ) to $3 \mathrm{dm}^{3}$ of a solution containing $0.25 \mathrm{kmol} \mathrm{m}^{-3}$ iron(III) nitrate $\left(\mathrm{Fe}\left(\mathrm{NO}_{3}\right)_{3} \cdot 9 \mathrm{H}_{2} \mathrm{O}\right.$, Merck P.A.) and $0.16 \mathrm{kmol} \mathrm{m}^{-3}$ manganese(II) nitrate $\left(\mathrm{Mn}\left(\mathrm{NO}_{3}\right)_{2} \cdot 4 \mathrm{H}_{2} \mathrm{O}\right.$, Riedel P.A.), which was heated to $365 \mathrm{~K}$. An atomic ratio of $\mathrm{Fe}: \mathrm{Mn}$ of 1.54 was used. The ammonia addition was stopped when a $\mathrm{pH}$ of 8 was reached. The precipitate was filtered off and washed with $200 \mathrm{~cm}^{3}$ distilled water. The catalyst was dried at $395 \mathrm{~K}$ for $24 \mathrm{~h}$ and calcined at $675 \mathrm{~K}$ for one $h$. In all experiments a sieve fraction of $0.2-0.6 \mathrm{~mm}$ was used.

In the same way, manganese oxide was obtained starting from only manganese(II) nitrate.

A sulphated catalyst was prepared by suspending sufficient iron manganese oxide catalyst in an ammonium sulphate solution $\left(0.01 \mathrm{kmol} \mathrm{m}^{-3}\left(\mathrm{NH}_{4}\right)_{2} \mathrm{SO}_{4}\right.$, Merck P.A.) to give an $\mathrm{Fe} / \mathrm{S}$ atomic ratio of $200: 1$. The water was evaporated at $368 \mathrm{~K}$ while the catalyst mass was stirred continuously. Thereafter, the same procedure was followed as is described in the unsulphated catalyst preparation after the filtration. After reduction with $\mathrm{H}_{2}$ the catalyst had atomic ratios of $\mathrm{Fe}: \mathrm{Mn}: \mathrm{S}$ of 1.54:1:0.008. According to electron microprobe results, the sulphur containing groups were present as large clusters on the catalyst surface.

The experimental methods and analytical procedures have been described in a previous paper [4]. From carbon monoxide and hydrogen adsorption measurements, we estimate the sulphated and unsulphated catalysts to have an exposed iron surface of about $1.2 \mathrm{~m}^{2} \mathrm{~g}^{-1}$. 
Nomenclature

The hydrocarbon reaction rate $r$ is defined as the number of $\mu$ moles of $C 0$ converted into $C_{1}$ through $C_{3}$ hydrocarbons per $\mathrm{kg}$ of iron per second. The selectivity $\mathrm{S}_{j}$ is defined as the ratio of the rate $r_{j}$ of formation of the product $j$ to the overall reaction rate:

$s_{j}=r_{j} / r$

The following further abbreviations will be used in this paper: I.S, isomer shift; $\Delta E_{Q}$, electric quadrupole splitting of a doublet; $H_{\text {eff }}$, magnetic hyperfine fields; $\varepsilon^{\prime}$, line shift due to the interaction of the nuclear quadrupole moment with the electric field gradient in a magnetically split spectrum; A, total absorption of a spectrum.

\section{Catalyst testing}

Mössbauer spectra of the catalysts before and after reduction were analysed by fitting sets of Lorentzian line shapes to the observed spectra with the aid of a least squares method. In order to obtain results of physical significance, a number of constraints was imposed on the final fits to the spectra:

(i) Peaks belonging to the same subspectrum should have equal widths,

(ii) In the case of a doublet peak, intensities should be equal,

(iii) For a magnetically split spectrum or sextuplet, the intensities of the first and the sixth, of the second and the fifth and of the third and the fourth peaks should be pairwise equal,

(iv) Distances between peaks in the same sextuplet should satisfy the ratios following from the different g-factors for the ground and excited level of the ${ }^{57} \mathrm{Fe}$ nucleus. In the presence of an electric field gradient (EFG) these ratios must be corrected for the interaction of the nuclear quadrupole moment with the EFG.

The more complex Mössbauer spectra of catalysts after Fischer Tropsch synthesis were analysed by fitting a linear combination of single-phase spectra of the constituents.

\section{RESULTS}

The iron manganese oxide catalyst before and after reduction

Figure 1 shows the Mössbauer spectra of the unreduced catalyst recorded at $4.2 \mathrm{~K}$, $77 \mathrm{~K}$ and $259 \mathrm{~K}$. The spectra obtained at room temperature have been analysed with the 'Lorentzian fitting procedure'; the results are listed in Table 1. The spectra show two components, labelled I and II.

Component I has the I.S. and $\varepsilon^{\prime}$ of $\alpha-\mathrm{Fe}_{2} \mathrm{O}_{3}$, but $\mathrm{H}_{\text {eff }}(507 \pm 2 \mathrm{kOe})$ is significantly lower than the $515 \mathrm{kOe}$ field of bulk $\alpha-\mathrm{Fe}_{2} \mathrm{O}_{3}$. The subspectrum of component $\mathrm{I}$ at 


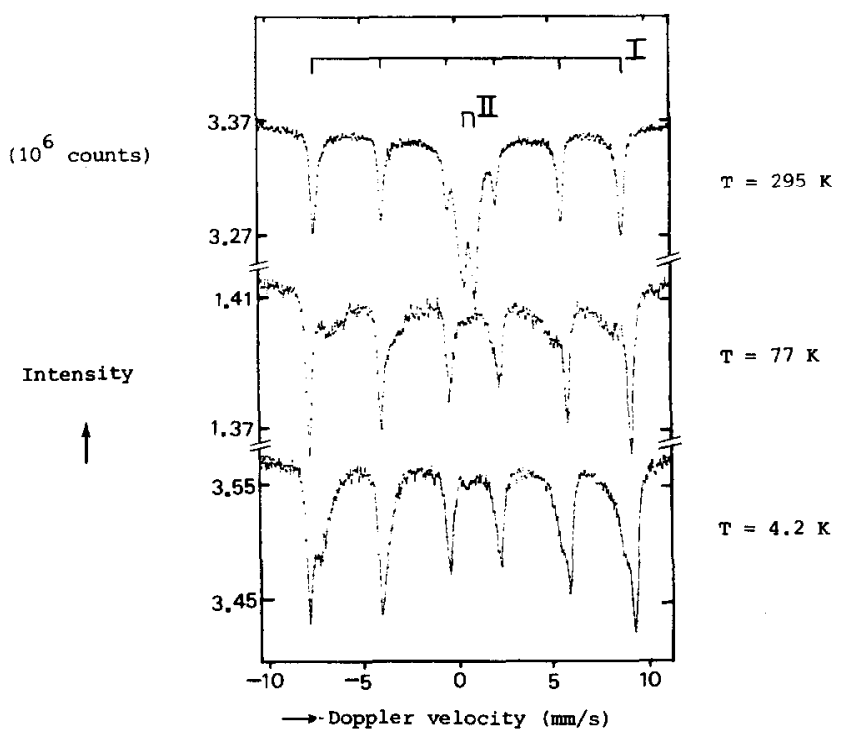

FIGURE 1 Mössbauer spectra of the manganese oxide promoted iron catalyst recorded at the indicated temperatures before reduction.

\section{TABLE 1}

Mössbauer parameters at $T=295 \mathrm{~K}$ of catalysts before and after reduction.

\begin{tabular}{lrccccc}
\hline & Component & $\begin{array}{c}\text { I.S. }^{*} \\
/ \mathrm{mm} \mathrm{s}^{-1}\end{array}$ & $\begin{array}{c}\Delta \mathrm{E}_{\mathrm{Q}} \\
/ \mathrm{mm} \mathrm{s}^{-1}\end{array}$ & $\begin{array}{c}\varepsilon^{\prime} \\
/ \mathrm{mm} \mathrm{s}^{-1}\end{array}$ & $\begin{array}{c}\mathrm{H}_{\text {eff }} \\
/ \mathrm{kOe}\end{array}$ & $\begin{array}{c}\text { Relative } \\
\text { area } / \%\end{array}$ \\
\hline Before & I & $0.64 \pm 0.03$ & - & $0.09 \pm 0.03$ & $507 \pm 2$ & 54 \\
reduction & II & $0.59 \pm 0.02$ & $0.67 \pm 0.02$ & - & - & 46 \\
After & I & $0.26 \pm 0.03$ & - & $0.00 \pm 0.01$ & $332 \pm 2$ & 80 \\
reduction & II & $0.48 \pm 0.06$ & $0.55 \pm 0.06$ & - & - & 7 \\
& II I & $1.35 \pm 0.06$ & $0.63 \pm 0.06$ & - & - & 13 \\
\hline
\end{tabular}

* Relative to the standard NBS Standard SNP.

$295 \mathrm{~K}$ is slightly asymmetrically broadened towards the lower hyperfine splittings. This broadening and the reduced value of $\mathrm{H}_{\text {eff }}$ indicate that $\alpha-\mathrm{Fe}_{2} \mathrm{O}_{3}$ is present in small particles, with a distribution of particle diameters. Following Van der Kraan [10] an average diameter of $23 \pm 2 \mathrm{~nm}$ can be estimated for these $\alpha-\mathrm{Fe}_{2} \mathrm{O}_{3}$ particles.

Component II shows a doublet at $295 \mathrm{~K}$, but is magnetically split at $77 \mathrm{~K}$ and $4.2 \mathrm{~K}$, with a broad distribution in $\mathrm{H}_{\text {eff }}$. The average value of $\mathrm{H}_{\text {eff }}$ at $77 \mathrm{~K}$ and $4.2 \mathrm{~K}$, and also the $\mathrm{I} . \mathrm{S}$. and $\Delta \mathrm{E}_{\mathrm{Q}}$ at $295 \mathrm{~K}$, are characteristic of small particles of $\alpha-\mathrm{FeOOH}$, 
with a distribution in particle diameters. Based on the average hyperfine field and on the fact that the superparamagnetic transition temperature is lower than $295 \mathrm{~K}$, it can be concluded [10] that the crystallite diameter is smaller than $8.5 \mathrm{~nm}$.

It should be noted that estimates of particle diameters are presented under the assumption that Van der Kraan's results, obtained with samples of small particles of $\alpha-\mathrm{Fe}_{2} \mathrm{O}_{3}$ or $\alpha-\mathrm{FeOOH}$, apply also to our samples in which $\mathrm{Mn}_{2} \mathrm{O}_{3}$ is also present.

According to $X$-ray diffraction data, the unreduced catalyst consists of $\alpha-\mathrm{Fe}_{2} \mathrm{O}_{3}$, $\alpha-\mathrm{FeOOH}$ and also $\mathrm{Mn}_{2} \mathrm{O}_{3}$. The relevant part of the $\mathrm{X}$-ray diffraction pattern of the reduced pure manganese oxide is shown in Figure $2 A$. These data agree with the pattern of Mn0, as is seen from Table 2.

TABLE 2

$X$-ray diffraction data of reduced $\mathrm{Mn}_{2} \mathrm{O}_{3}$ samples for angles $2 \theta$ between $40^{\circ}$ and $80^{\circ}$.

\begin{tabular}{crcc}
\hline & & Mn0 & \\
This study & & Swanston et aT. [11] \\
$2 \theta$ & $1 / \%$ & $2 \theta$ & $1 / \%$ \\
\hline $44.4 \pm 0.1$ & 45 & 44.52 & 60 \\
$51.6 \pm 0.1$ & 100 & 51.66 & 100 \\
$76.2 \pm 0.1$ & 50 & 76.26 & 60 \\
\hline
\end{tabular}

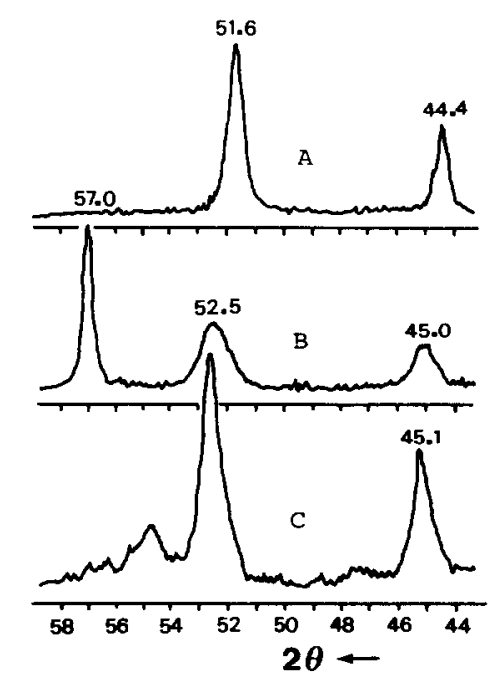

FIGURE 2 X-ray diffraction patterns of A) manganese oxide, Mn0, B) a reduced manganese oxide promoted iron catalyst and C) as B after $16 \mathrm{~h}$ of Fischer Tropsch reaction at $513 \mathrm{~K}$. 
Mössbauer spectra of the iron manganese oxide catalyst after reduction are shown in Figure 3. The spectrum obtained at room temperature was analysed with the 'Lorentzian fitting procedure' as a combination of a sextuplet, labelled I, and two doublets, labeelled II and III respectively. See Table 1 for the numerical results.

TABLE 3

Hyperfine fields $H_{\text {eff }}$ in the catalysts before and after reduction.

\begin{tabular}{lcccc}
\hline & & \multicolumn{3}{c}{$\mathrm{H}_{\text {eff }} / \mathrm{kOe}$} \\
& Component & $295 \mathrm{~K}$ & $77 \mathrm{~K}$ & $4.2 \mathrm{~K}$ \\
\hline Before & I & $507 \pm 2$ & $503 \pm 2$ & $537 \pm 2$ \\
reduction & II & - & $470 \pm 5^{*}$ & $502 \pm 5^{\star}$ \\
After & I & $332 \pm 2$ & $339 \pm 2$ & $341 \pm 2$ \\
reduction & II & - & $495 \pm 5^{\star}$ & $513 \pm 5^{*}$ \\
\hline \multirow{2}{*}{ Average value } & & &
\end{tabular}

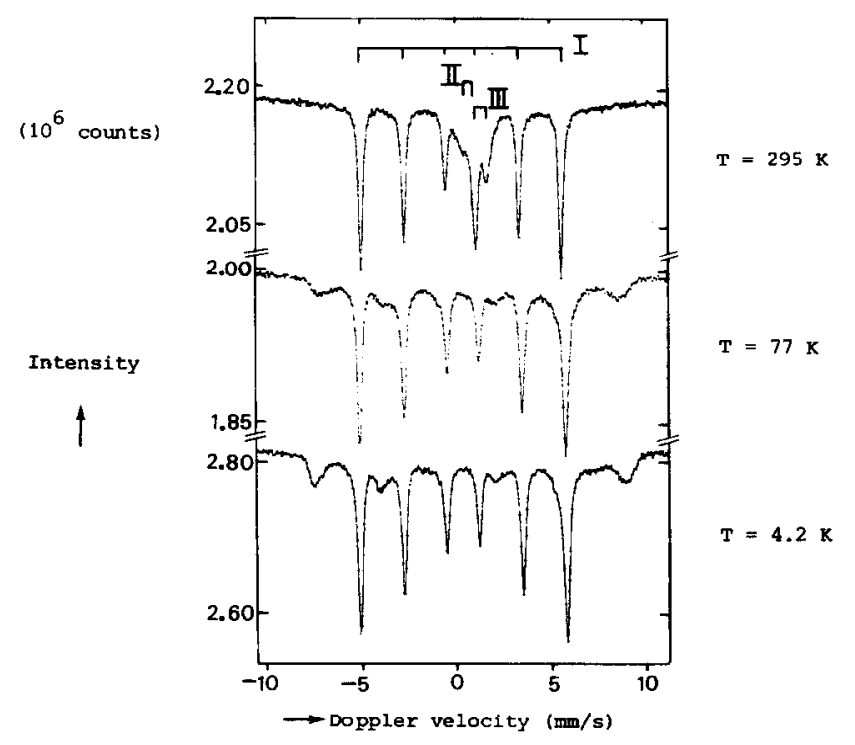

FIGURE 3 Mössbauer spectra of the manganese oxide promoted iron catalyst recorded at the indicated temperature after the reduction.

Component I is easily identified as $\alpha-\mathrm{Fe}$. The parameters of component II are those of a paramagnetic $\mathrm{Fe}^{3+}$ compound, while the parameters of component III are more indicative of $\mathrm{Fe}^{2+}$, al though $\Delta \mathrm{E}_{\mathrm{Q}}$ is rather small for a $\mathrm{Fe}^{2+}$ compound. 
At temperatures of $77 \mathrm{~K}$ and $4.2 \mathrm{~K}$, components II and III are magnetically split, each with a distribution in hyperfine fields. Estimated averages of $\mathrm{H}_{\text {eff }}$ for component II are given in Table 3; these values support the conclusion that II is a $\mathrm{Fe}^{3+}$ compound. The subspectrum of component III is very broad and difficult to observe at these low temperatures, so that even a rough estimation of its Mössbauer parameters seems hardly warranted.

The contribution of $\alpha-F e$ to the Mössbauer spectrum obtained at $295 \mathrm{~K}$ is $(80 \pm 3) \%$, so it can be concluded that the main part of the iron oxide that was present in the precipitated catalyst has been reduced.

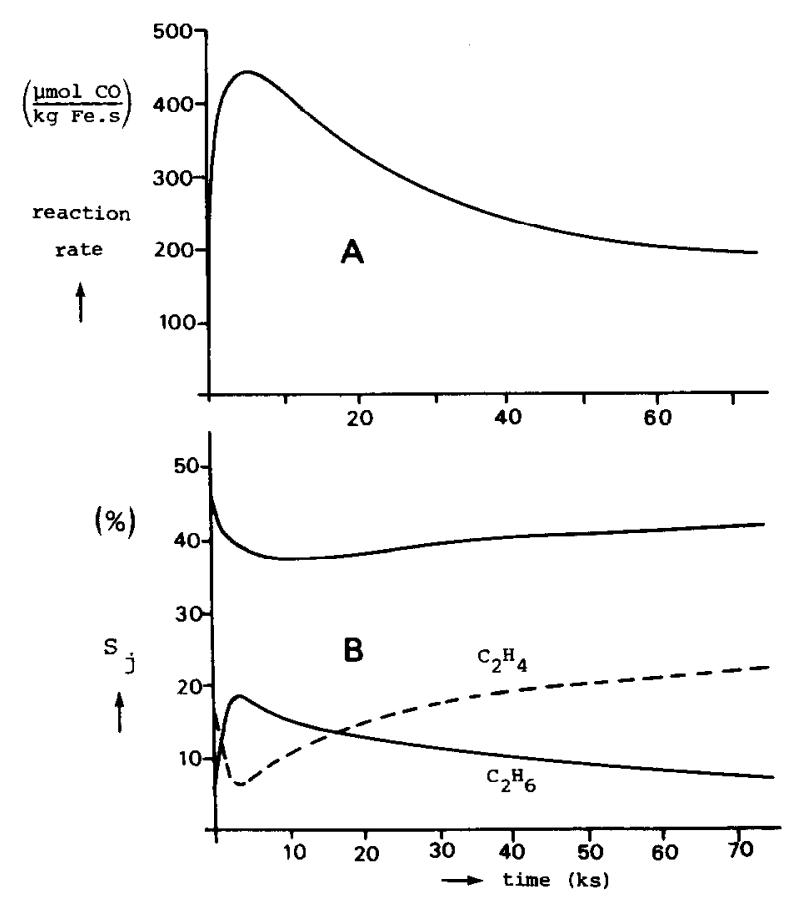

FIGURE 4 A) Reaction rate during Fischer Tropsch synthesis on a Fe/Mn0 catalyst at $513 \mathrm{~K}, \mathrm{~B})$ the corresponding methane, ethane and ethene selectivities.

The $X$-ray diffraction pattern (see Figure $2 B$ ) showed clearly the diffraction line of reduced iron (at $2 \theta=57^{\circ}$ ), while the compounds containing $\mathrm{Fe}^{2+}$ ar, $\mathrm{Fe}^{3+}$ were not observed, probably because of their small dimensions. A remarkable shift of the MnO diffraction lines occurred in the direction of the $\alpha-F e$ diffraction line, which cannot be explained by the spinel structures of iron and manganese oxide. It is likely that this shifted Mno pattern and the presence of the unreduced iron compounds containing $\mathrm{Fe}^{2+}$ and $\mathrm{Fe}^{3+}$ reflects the interaction between the iron 
compounds and the promotor Mno.

Fischer Tropsch synthesis on an iron manganese oxide catalyst

The composition of the catalyst during the synthesis at $513 \mathrm{~K}$ was studied by Mössbauer spectroscopy and X-ray diffraction analysis; for this a number of catalysts after increasing periods of reaction was investigated. For each experiment a fresh catalyst sample was used, taken from the same batch of unreduced material.

With the promoted catalyst we found differences of about $10 \%$ in the reaction rate between the various experiments after the same period of Fischer Tropsch synthesis. The accuracy of the product analysis itself was better than $1 \%$. Probably the differences observed were due to poor reproducibility of the reduction of these promoted catalysts. Because the product distributions did not differ and the general shape of the curves of the reaction rate were comparable, we believe that these experiments still give a good qualititive picture of the catalyst behaviour during the Fischer Tropsch reaction. The reaction rate and the selectivities for methane, ethane and ethene are shown in Figure 4.

This catalyst needed about $5 \mathrm{ks}$ before the maximum activity was reached; in that period the ethane to ethene ratio increased drastically, as is shown in Figure 5. During the deactivation of the catalyst the ethane to ethene ratio decreased again. The ethene selectivities of the Mno promoted and pure iron catalysts were about equal at corresponding reaction periods.

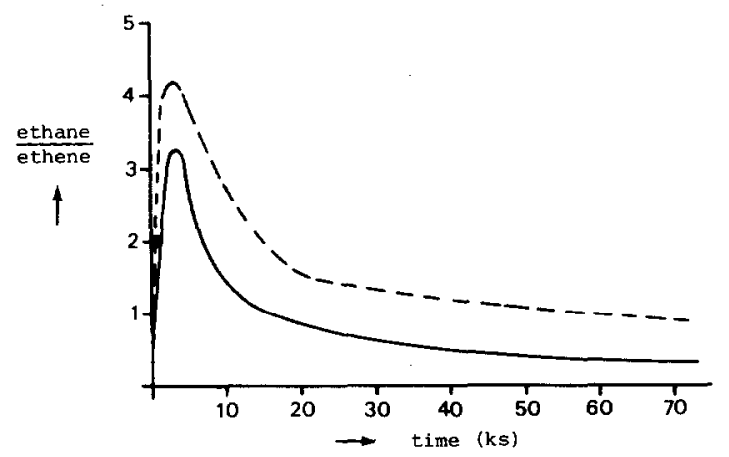

FIGURE 5 Ethane to ethene ratio during Fischer Tropsch synthesis over an unsulphated (solid line) and a sulphated (broken line) Fe/Mno catalyst at $513 \mathrm{~K}$.

Fischer Tropsch synthesis at $513 \mathrm{~K}$ on several iron manganese oxide catalysts with differing manganese oxide contents showed no relation between the olefin selectivity of the catalyst and the amount of manganese oxide added.

Mössbauer spectra of the catalyst after various periods of Fischer Tropsch synthesis at $513 \mathrm{~K}$ are shown in Figure 6 . The spectra were analysed by fitting a 


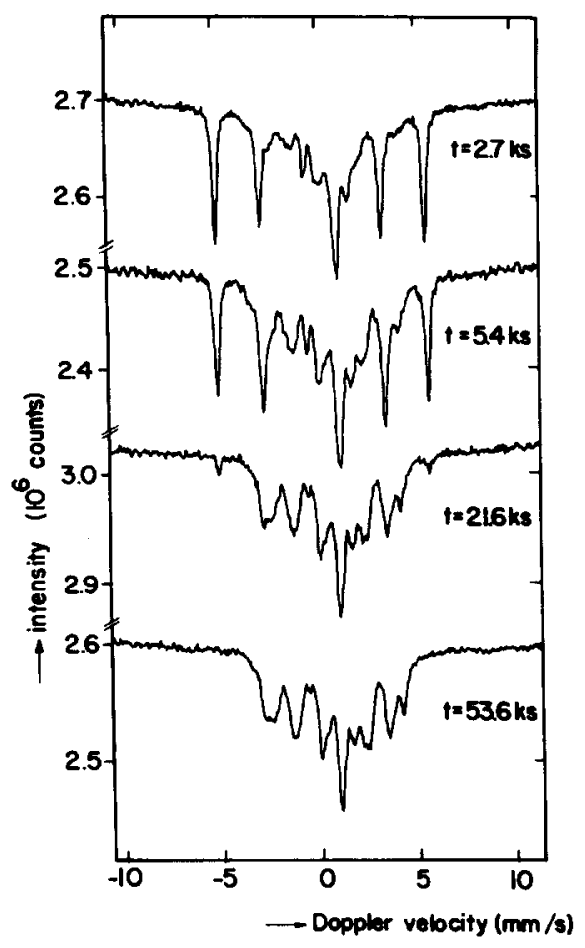

FIGURE 6 Mössbauer spectra of the reduced $\mathrm{Fe} / \mathrm{MnO}$ catalyst after different periods of Fischer Tropsch synthes is at $513 \mathrm{~K}$. Spectra were recorded at room temperature.

linear combination of base spectra to the measured spectra. The Mössbauer spectra which were used as a base are the single phase carbide spectra used in our previous study [4], completed with the spectra of $\alpha$-Fe and the subspectra of doublets belonging to the unreduced iron phases in the catalyst after reduction. Results of this analysis are shown in Figure 7.

According to the rossbauer spectra and the $X$-ray diffraction pattern (Figure 6 ), the $\alpha-F e$ is converted into the carbides $\varepsilon^{\prime}-\mathrm{Fe}_{2.2} \mathrm{C}$ and $\mathrm{X}-\mathrm{Fe}_{5} \mathrm{C} \mathrm{C}_{2}$. In this conversion $\mathrm{Fe}_{\mathrm{x}} \mathrm{C}$, which is known from our Mossbauer and $\mathrm{X}$-ray investigation to represent poorly defined structures between $\alpha-F e$ and a crystallographically well defined carbide, appears as an intermediate.

The X-ray diffraction lines of MnO are still the same as those in Figure 2B; because the contribution of the unreduced iron phases $\mathrm{Fe}^{2+}$ and $\mathrm{Fe}^{3+}$ is also constant during the time interval studied, these results indicate that during the fischer Tropsch synthesis not much reduction or oxidation of the catalyst occurs.

When the synthesis gas mixture is led over pure MnO, no reaction products are formed at $513 \mathrm{~K}$. 


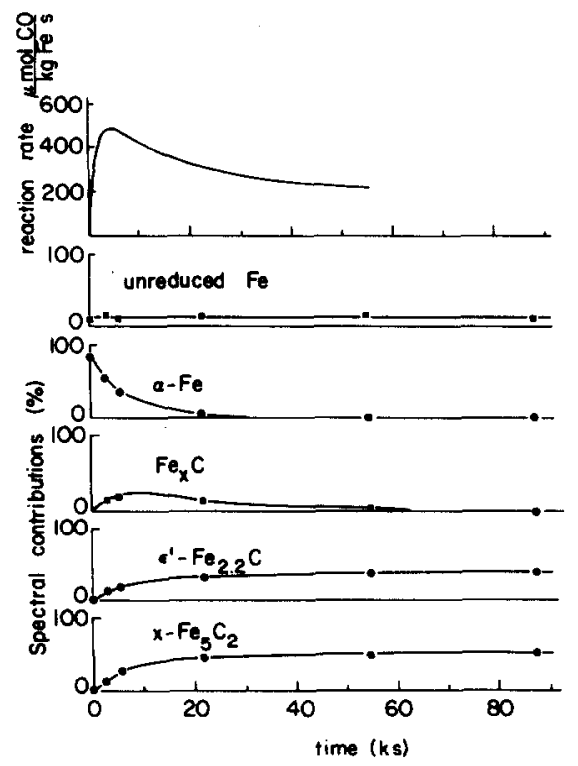

FIGURE 7 Reaction rates (upper curve) and relative contributions of reduced $\mathrm{Fe}$, unreduced $\mathrm{Fe}$ and the various carbides to the Mossbauer spectra during the Fischer Tropsch synthesis over a reduced $\mathrm{Fe} / \mathrm{MnO}$ catalyst at $513 \mathrm{~K}$.

Fischer Tropsch synthesis on sulphur containing iron manganese oxide catalysts

The reaction rate and the selectivities of the sulphate impregnated iron manganese oxide at $513 \mathrm{~K}$ are shown in Figure 8 . The maximum reaction rate is lower than the maximum rate of the original iron manganese oxide catalyst but, as the final activities are about equal, evidently the sulphated catalyst also deactivates less. The smaller deactivation is accompanied by a higher ethane to ethene ratio during the complete time interval studied, as is shown in Figure 5.

The Mössbauer spectrum of the reduced sulphated catalyst contains contributions of the same subspectra as the unsulphated catalyst, only the contribution of $\alpha-\mathrm{Fe}$ for the former is less, so the degree of reduction is somewhat lower for the sulphated catalyst.

However, after a reaction period of $30 \mathrm{ks}$ iron is still present in the sulphated catalyst (see Figure 9); probably the sulphur compounds prevent this iron from being carbided by the synthesis gas. The composition of the spectra with respect to the carbides is not essentially different. Here also the phase $\mathrm{Fe}_{\mathrm{x}} \mathrm{C}$ remains visible in the spectra as long as $\alpha-\mathrm{Fe}$ is present.

In the introduction we mentioned that manganese oxide has been advocated as an effective promotor of Fischer Tropsch catalysts to produce light olefins. Because the unsulphated as well as the sulphated iron manganese oxide catalysts behave at 


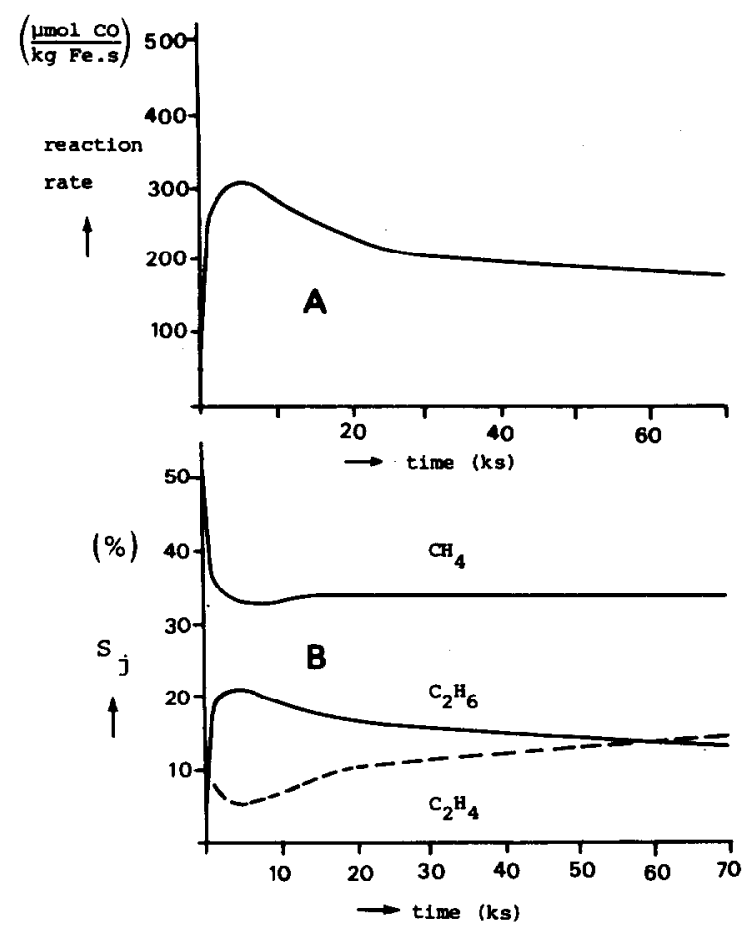

FIGURE 8 A) Reaction rate during Fischer Tropsch synthesis on a sulphated Fe/MnO catalyst at $513 \mathrm{~K}$. B) The corresponding methane, ethane and ethene selectivities.

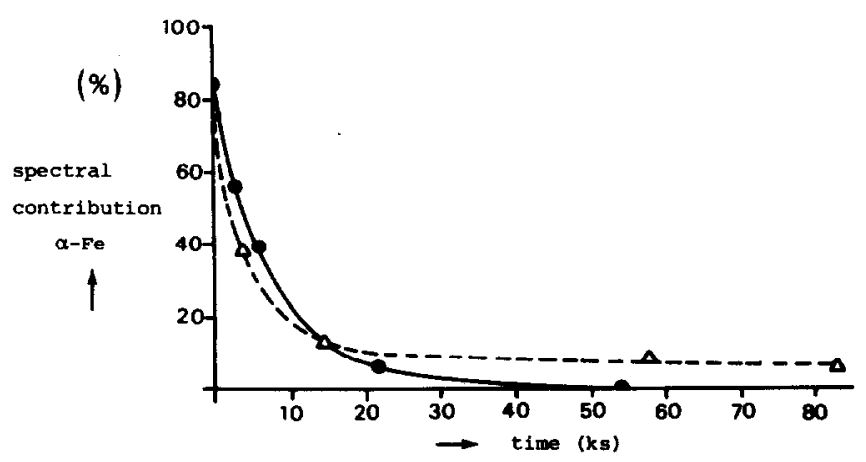

FIGURE 9 Relative contributions from reduced $\alpha$-Fe to the Mossbauer spectra during Fischer Tropsch synthesis over A) an unsulphated $\mathrm{Fe} / \mathrm{MnO}$ catalyst ( $(\bullet)$ and $\mathrm{B}$ ) a sulphated $\mathrm{Fe} / \mathrm{MnO}$ catalyst $(\Delta)$ at $513 \mathrm{~K}$.

$513 \mathrm{~K}$ in about the same way as a pure iron catalyst, i.e., no beneficial influence on the olefinicity is found at this temperature; the catalysts were further studied 
at a reaction temperature of $623 \mathrm{~K}$.

At $623 \mathrm{~K}$ the reaction rate of the pure iron catalyst increases very quickly, but the catalyst is deactivated within $3.6 \mathrm{ks}$ by the formation of inactive graphite carbon species (after a short initial period of a few minutes the carbon deposition increases at a constant rate of 3 wt $\%$ carbon $h^{-1}$ ). The methane selectivity varies between 80 and $90 \%$.

The activation and deactivation of the manganese oxide promoted iron catalyst proceeds at $623 \mathrm{~K}$ just as found for the pure iron catalyst, although a little more activity remains (see Figure 10 ) and the main product is also methane.
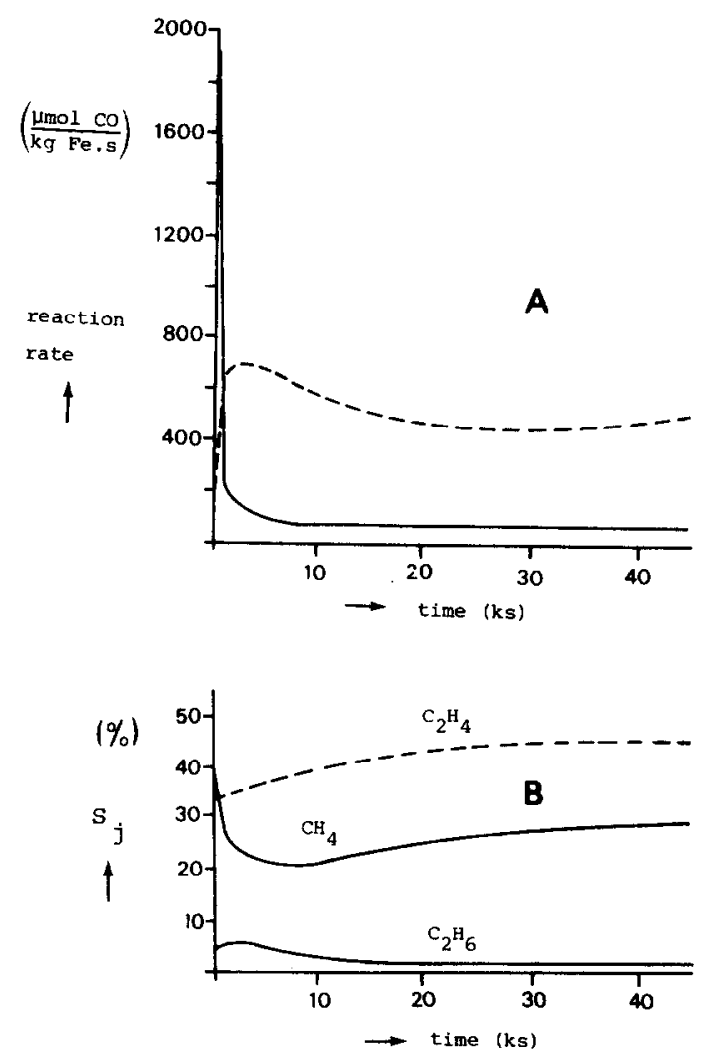

FIGURE 10 Reaction rates during Fischer Tropsch synthesis at $623 \mathrm{~K}$ over $A$ ) an unsulphated $\mathrm{Fe} / \mathrm{MnO}$ catalyst (solid line) and over a sulphated $\mathrm{Fe} / \mathrm{MnO}$ catalyst (broken line); B) the methane, ethane and ethene selectivities on a sulphated $\mathrm{Fe} / \mathrm{MnO}$ cataiyst.

However, the sulphate impregnated iron manganese oxide catalyst behaves totally differently at $623 \mathrm{~K}$, as is also shown in Figure 10 . The catalyst is again quickly 
activated, but the reaction rate remains rather high. Even more remarkable is the observation that the main product is no longer methane, but ethene. The ethane/ethene ratio levels out to a value of about 0.03 after $50 \mathrm{ks}$ Fischer Tropsch reaction at $623 \mathrm{~K}$.

Unfortunately, the mechanical strength of this particular sulphated catalyst was much lower than that of the unsulphated iron manganese oxide catalyst. On the sulphated as well as the unsulphated catalyst very much carbon is deposited at $623 \mathrm{~K}$, but the sulphated catalyst particles disintegrate to a fine powder after a few hours; this effect causes a slow increase in the reaction rate after $25 \mathrm{ks}$.

The addition of higher quantities of ammonium sulphate to the iron manganese oxide catalyst results in an improved resistance against the deposition of carbon, thus preventing catalyst disintegration, while the olefin selectivity remains very high. However, the amounts of sulphate added have to be restricted to below 1 wt \% sulphur, otherwise the catalyst is completely deactivated. In our laboratory, Kieffer [12] has produced quantitative data about the optimum addition of sulphate to Fe/Zno catalysts and found these catalysts to be very stable and very selective.

\section{DISCUSSION}

The degree of reduction of the sulphated and unsulphated catalysts varies between 70 and $80 \%$. The rather sma11 quantities of unreduced $\mathrm{Fe}^{2+}$ and $\mathrm{Fe}^{3+}$ compounds are observed as superparamagnetic phases in Mossbauer spectroscopy; these compounds also cause the shift of the X-ray diffraction lines of Mno. During the Fischer Tropsch reaction the amount of the unreduced iron does not change. These unreduced iron compounds are probably associated with the Mno phase of the catalyst. Reduction at higher temperatures leads to a lower activity, presumably due to sintering.

The increase of the reaction rates on unsulphated and sulphated catalysts during the first $3 \mathrm{ks}$ at $513 \mathrm{~K}$ was accompanied by an increase of the ethane to ethene ratio. This was also observed on pure iron catalysts by 0tt et a1. [13] and also in our laboratory. As we have some indications from experiments in our laboratory $[12,14]$ that the hydrogenation reactions involved in the formation of methane and in the formation of higher paraffins are different in nature, we will, for a discussion of the hydrogenation activity, restrict ourselves to a comparison of the formation of ethane and ethene, as we may assume that these products are formed from the same precursor. In a recent kinetic study, Rautavuoma and Van der Baan [15] conclude that the precursors $\mathrm{C}_{n} \mathrm{H}_{2 n}{ }^{* *}$ are bound to the catalyst surface with one carbon atom to two metal sites. We will thus assume that ethane and ethene are formed according to the following reactions:

$\mathrm{C}_{2} \mathrm{H}_{4} * \underset{k_{-1}}{\stackrel{k_{1}}{\gtrless} \mathrm{C}_{2} \mathrm{H}_{4}}+2^{*} \quad$ fast equilibrium 
and

$\mathrm{C}_{2} \mathrm{H}_{4}^{* \star}+2 \mathrm{H}^{*} \stackrel{\mathrm{k}_{2}}{\stackrel{2}{\rightleftarrows}} \mathrm{C}_{2} \mathrm{H}_{6}+4^{\star}$

The formation rates of these products can be expressed as:

$r_{C_{2} H_{4}}=\left(C_{2} H_{4}\right) \cdot \frac{F}{W}=\frac{{ }^{k \theta} C_{2} H_{4}}{{ }_{e}{ }^{2}} \cdot \frac{F}{W}$

and

$r_{\mathrm{C}_{2} \mathrm{H}_{6}}=\frac{d\left(\mathrm{C}_{2} \mathrm{H}_{6}\right)}{\mathrm{dt}}=k_{2} \cdot{ }^{\theta} \mathrm{C}_{2} \mathrm{H}_{4} \cdot{ }^{\theta_{H}}{ }^{2}$

where $F$ is the gas rate in $\mathrm{m}^{3} \mathrm{~s}^{-1}$, W the catalyst weight in $\mathrm{kg},\left(\mathrm{C}_{2} \mathrm{H}_{4}\right)$ the concentration of ethene in $k m 01 \mathrm{~m}^{-3}$ and $k$ the ratio between $k_{1}$ and $k_{-1}$.

As (2) and (3) are parallel reactions starting from the same substrate we can write:

$\frac{{ }_{\mathrm{C}_{2} \mathrm{H}_{6}}}{r_{\mathrm{C}_{2} \mathrm{H}_{4}}}=k^{\prime} \cdot \theta_{e}{ }^{2} \cdot \theta_{H}{ }^{2} \cdot \frac{W}{F}$

The surface coverage of empty sites $\theta_{e}$ will presumably decrease in the course of a reaction and therefore can initially not be very low. The low ethane to ethene ratio is then caused by either a low surface coverage of hydrogen $\theta_{\mathrm{H}}$ or by a low number of ensembles of sites that can perform the hydrogenation reaction. Since we expect that the equilibrium of the dissociative hydrogen adsorption is quickly reached, we suggest that $k^{\prime}$ must increase in the course of the reaction, i.e., that the iron surface requires first some kind of activation by which action the hydrogenation ensembles are formed.

If we would assume with Sachtler et a1. [17] that the surface compounds are of the composition $\mathrm{C}_{n} \mathrm{H}_{2 n+1}$ and single bonded, we can derive relations that lead to the same conclusions as have been derived on the basis of equation (6).

The deactivation of the catalysts is accompanied by a decrease of the ethane to ethene ratios. This decrease can be caused by carbon deposition that results in a decrease of either the hydrogenation ensembles mentioned above or of the empty sites $\theta_{e}$, or even of both. The former factor influences $k^{\prime}$ of equation (6), whereas the latter has its influence on both $\theta_{e}$ and $\theta_{H}$.

As during the overall deactivation process the rate of ethene formation actually increases, we are inclined to ascribe this deactivation to a decrease in empty 
sites, for that would, according to equation (4), explain the observed rate increase for ethene.

As opposed to an iron catalyst a cobalt catalyst has a high initial activity; on these cobalt catalysts some deactivation is observed, which is also coupled with a decreasing ethane to ethene ratio [16].

During the activation/deactivation process the sulphated catalyst is always somewhat less active than the unsulphated catalyst, although in the final (pseudo) steady state the difference in activity is small. It is noteworthy that during the whole activation/deactivation process at $513 \mathrm{~K}$ the ethane to ethene ratio is higher for the sulphated catalyst than for the unsulphated catalyst.

Since no relation has been found at $513 \mathrm{~K}$ between the olefin selectivity of the catalyst and the amount of manganese oxide added, the manganese oxide itself is not considered to be an effective promotor for the production of 1 ight olefins. This is not in agreement with the results of Kölber [1], Büssemeier [2] and Yang [3]. We also did not observe any influence of manganese oxide additions on the molecular mass distribution of the product mixture. A fully carburized iron manganese oxide catalyst revealed a Schulz-Flory distribution which was quite similar to that of a carburized iron catalyst without manganese oxide.

However, a great difference between sulphated and unsulphated catalysts is observed at higher temperatures. The sulphated catalysts are stable at $623 \mathrm{~K}$ and give a product with a high olefin content and a relatively low $\mathrm{CH}_{4}$ production, whereas the unsulphated catalyst deactivates quickly and produces only methane. Kieffer [12] has argued that the effect of sulphur is basically an increased stability of the catalyst at higher temperatures and that the higher olefinicity is mainly caused by the higher reaction temperature.

Results comparable to those we obtained with sulphated catalysts at $623 \mathrm{~K}$ were obtained by Büssemeier [2] with manganese promoted iron catalysts. In connection with our negative results with manganese oxide alone, we are inclined to think that the olefin selectivity of the catalysts of Buissemeier is caused by one of the other further promotors that are added to his catalysts, or to the use of less pure starting materials.

\section{REFERENCES}

1 H. Kölbel and K.D. Tillmetz, Deutsches Offen., 2507647 (1976).

2 B. Büssemeier, C.D. Fröhning, G. Horn and W. Kluy, Deutsches Offen., 2518964 (1976).

3 C.H. Yang and A.G. Ablad, Paper presented at the Symposium on Advances in F.T. Chemistry, Anaheim meeting, March 1978.

4 J.W. Niemantsverdriet, A.M. van der Kraan, W.L. van Dijk and H.S. van der Baan, J. Phys. Chem., 84 (1980) 3363.

5 I.G. Farbenindustrie Aktiengesellschaft, British Patent 322284 (1929).

6 W.W. Myddleton, British Patent, 509325 (1939).

7 E.T. Layng, U.S. Patent, 2446426 (1948).

8 R.A. Dalla Betta, A.G. Piken and M. Shelef, J. Catal., 40 (1975) 173. 
9 R.J. Madon and H. Shaw, Catal. Rev. Sci. Eng., 15 (1977) 69.

10 A.M. van der Kraan, Thesis, University of Technology, Delft, 1972.

11 M. Swanson et al., NBS circular 539545 (1955).

$12 \mathrm{E}$. Ph. Kieffer, Thesis, Eindhoven University of Technology, 1981.

13 G.L. Ott, T. Fleisch and W.N. Delgass, J. Catal., 65 (1980) 253.

14 W.L. van Dijk and H.S. van der Baan, to be published.

15 A.0.I. Rautavuoma and H.S. van der Baan, Appl. Catal., 1 (1981) 247.

16 A.0.I. Rautavuoma, Thesis, Eindhoven University of Technology, 1979.

17 W.M. Sachtler, P. Biloen and J.N. Helle, Paper presented at the IVth Int. Conf on Heterogeneous Catalys is, Varna, 1979. 